\title{
DO 18 CARAT GOLD SOLDERS EXIST?
}

\author{
G. Humpston* \& D.M. Jacobson \\ Hirst Research Centre \\ GEC-Marconi Ltd. \\ Borehamwood, U.K.
}

For an alloy to be classified as an 18 carat yellow gold solder it must have a melting point below $450{ }^{\circ} \mathrm{C}$, contain $75 \mathrm{wt} \%$ gold and have a colour that matches the hue of the jewellery gold. The constitution that the alloy must possess in order to have these properties is established. No known alloy simultaneously satisfies all three necessary criteria and it is argued that none is likely to exist.

However, it may be possible to formulate low melting point 22 carat gold solders. An alternative joining technology, diffusion soldering, is capable of meeting the essential requirements for joining articles of 18 carat gold and its capabilities are described. 


\section{INTRODUCTION}

The majority of gold jewellery is made to the 18 carat, yellow gold, hallmarking classification. It is traditionally manufactured by brazing together a number of intricate components, fabricated by casting or mechanical working, using the so-called carat gold solders. These filler metals, more correctly referred to as brazes, have typical working temperatures in the range $750-900{ }^{\circ} \mathrm{C}[1]$, Such temperatures are highly detrimental to the mechanical robustness of jewellery. This is because 18 carat gold anneals and softens rapidly when heated above about $450^{\circ} \mathrm{C}$. Figure 1 shows how the hardness of an 18 carat yellow gold (type $750 \mathrm{Y}-3)$ in the cold-rolled condition drops in the course of heat-treatment at 450 and $750^{\circ} \mathrm{C}$. Most of the cold-worked strength is removed by heating for more than a few seconds to typical brazing temperatures. Clearly, the jewellery industry could benefit from the availability of low melting point solders for 18 carat gold.

In this article the principal requirements for an 18 carat yellow gold solder will be identified and the alloy constitution necessary to meet them will be established. The likelihood of developing such an alloy will then be considered. Throughout, the conventional definition will be used to distinguish solders from brazes: solders are filler metals with melting points below $450^{\circ} \mathrm{C}$ whereas brazes are filler metals which melt above $450^{\circ} \mathrm{C}$.

\section{TARGET PROPERTIES}

The principal requirements of a true solder for 18 carat yellow gold jewellery are that it must:

i) have a gold concentration of $75 \mathrm{wt} \%$ in order to satisfy the hall-marking criterion

ii) be colour matched to the jewellery alloy, in the standard yellow hue, for aesthetic considerations

iii) have a melting point below $450^{\circ} \mathrm{C}$ so that the filler may be classified as a solder. The lower joining temperature offers benefits in enabling the soldering operation to be carried out without significantly softening the jewellery and in terms of simpler and cheaper heating methods.

These three specific criteria are absolute requirements. Other properties such as good wetting and spreading behaviour of the solder and the mechanical properties and resistance to corrosion and wear of joints are further considerations.

Gold is unusual in that it is the only metal on which both brazes and solders are based, i.e. this element is a major constituent of both types of filler [2]. As a first step in examining the solder possibilities it is therefore instructive to consider the existing gold brazes and evaluate the constitutional basis for their formulation.

\section{CARAT GOLD BRAZES}

A representative selection of 18 carat braze compositions used for jewellery applications is given in $\mathbf{T a}$ ble 1 . These alloys comprise $75 \mathrm{wt} \%$ gold, with the majority of the balance being made up of copper, silver and nickel. The remaining elements, which make up approximately $5-10 \mathrm{wt} \%$ of the alloy, are selected on the basis of their ability to depress the melting point of gold and sometimes also to influence some other physical property, such as hardness and malleability. These are low melting point elements, predominantly tin, zinc and cadmium. More recently, indium and gallium have tended to replace cadmium now that the toxicity of cadmium oxide fume is better appreciated.

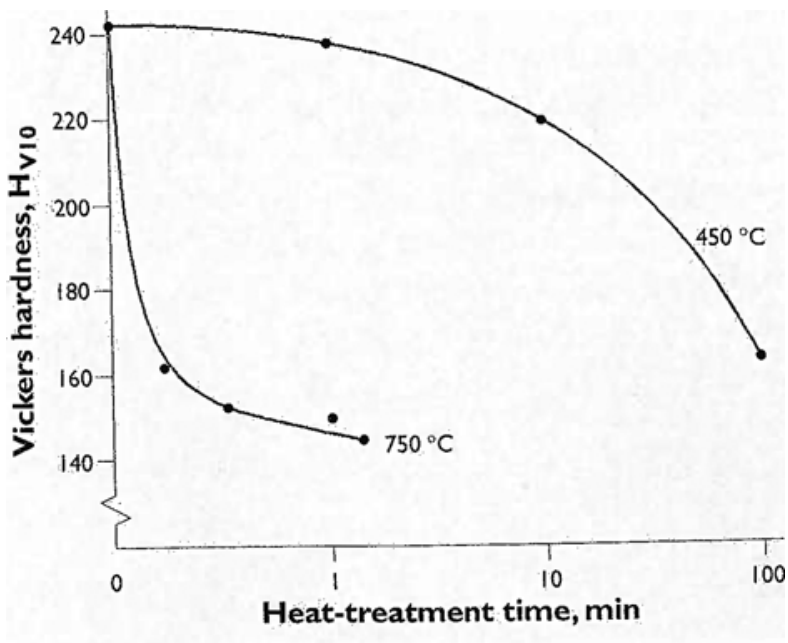

Figure 1

Annealing characteristics of cold-worked $18 \mathrm{ct}$ gold at two temperatures 


\begin{tabular}{|c|c|c|c|c|c|c|}
\hline \multirow{7}{*}{$\begin{array}{r}\text { Selected brazes for } 18 \text { carat gold } \\
\text { and their melting ranges }\end{array}$} & \multicolumn{5}{|c|}{ Composition, wt\% } & Melting range, ${ }^{\circ} \mathrm{C}$ \\
\hline & $75 \mathrm{Au}$ & $8 \mathrm{Ag}$ & $17 \mathrm{Cu}$ & & & $882-893$ \\
\hline & $75 \mathrm{Au}$ & $12 \mathrm{Ag}$ & $8 \mathrm{Cu}$ & $5 \mathrm{Sn}$ & & $826-887$ \\
\hline & $75 \mathrm{Au}$ & $9 \mathrm{Ag}$ & $6 \mathrm{Cu}$ & $10 \mathrm{Zn}$ & & $730-783$ \\
\hline & $75 \mathrm{Au}$ & $3 \mathrm{Ag}$ & $11 \mathrm{Cu}$ & $2 \mathrm{Cd}$ & $9 \mathrm{Zn}$ & $747-788$ \\
\hline & $75 \mathrm{Au}$ & $15 \mathrm{Cu}$ & $8 \mathrm{Cd}$ & $2 \mathrm{Zn}$ & & $793-822$ \\
\hline & $75 \mathrm{Au}$ & $12 \mathrm{Ni}$ & $5 \mathrm{Sn}$ & $8 \mathrm{Zn}$ & & $782-871$ \\
\hline
\end{tabular}

The phase diagrams of the established gold brazes share common features, taking the form shown schematically in Figure 2. The freezing point of gold is depressed by the alloying additions, as is the melting point, resulting in the brazes having a distinct melting range. It can be seen from the phase diagram that solidification of a $75 \mathrm{wt} \%$ gold alloy leads to a gold solid solution and this endows the braze and joints in which it is used with the desired golden hue. The microstructure of an 18 carat braze ( $75 \mathrm{Au}-12 \mathrm{Ni}-5 \mathrm{Sn}-8 \mathrm{Zn}$ wt $\%)$ is shown in Figure 3. Four phases can be seen but the dominant phase is clearly primary gold.

By extrapolation it is possible to calculate that, in order to depress the liquidus temperature of a binary alloy containing $75 \mathrm{wt} \%$ gold to below $450^{\circ} \mathrm{C}$, so that it falls within the ambit of a true solder, the alloying element would have to have a melting point of roughly $-1400^{\circ} \mathrm{C}$ ! Obviously, this is not an option. For fundamental thermodynamic reasons multiple additions to gold of elements with phase diagrams of the type shown in Figure 2, will be similarly incapable of depressing the melting point of gold below $450^{\circ} \mathrm{C}$. Therefore, 18 carat yellow gold solders must possess a different type of constitution.

\section{CARAT GOLD SOLDERS}

By definition, the temperature of a eutectic transformation must be below the melting points of the constituent phases. This type of phase change therefore offers scope for a large depression of the melting point of gold. Indeed the available gold solders belong to this category. A schematic phase diagram of a carat gold solder with this type of alloy constitution is shown schematically in Figure 4.

A list of the binary eutectic gold-based alloys used in engineering applications, which melt below $450{ }^{\circ} \mathrm{C}$, is given in Table 2 . These alloys are all goldrich compositions which fortuitously meet the minimum hall-marking specification for 18 carat gold, as they contain $75 \mathrm{wt} \%$ or more gold. Gold-silicon solders potentially could also be used with 22 carat jewellery. Furthermore, they are suitable for joining to gold jewellery due to the relatively high slope of the liquidus phase boundary between the various eutectic points and pure gold. In theory this characteristic should help ensure minimal erosion of jewellery parts by the molten solder and result in good penetration into long narrow joints.

\begin{tabular}{|c|c|c|c|c|c|c|}
\hline \multirow[b]{2}{*}{ Table 2} & \multicolumn{2}{|c|}{ Composition, wt\% } & \multirow{2}{*}{$\begin{array}{r}\begin{array}{r}\text { Eutectic } \\
\text { temp., }\end{array} \\
363^{\circ} \mathrm{C}\end{array}$} & \multirow{2}{*}{$\frac{\text { Caratage }}{23.3}$} & \multirow{2}{*}{$\begin{array}{c}\begin{array}{c}\text { Gold Phase, } \\
\text { vol.\% }\end{array} \\
84\end{array}$} & \multirow{2}{*}{$\begin{array}{c}\text { Colour } \\
\text { golden }\end{array}$} \\
\hline & $97 \mathrm{Au}$ & $3 \mathrm{Si}$ & & & & \\
\hline & $88 \mathrm{Au}$ & $12 \mathrm{Ge}$ & $361^{\circ} \mathrm{C}$ & 21.1 & 68 & pale gold \\
\hline eutectic alloys & $75 \mathrm{Au}$ & $25 \mathrm{Sb}$ & $360^{\circ} \mathrm{C}$ & 18.0 & 50 & grey white \\
\hline $\begin{array}{l}\text { *) the gold is present } \\
\text { only in intermetallic }\end{array}$ & $80 \mathrm{Au}$ & $20 \mathrm{Sn}$ & $278^{\circ} \mathrm{C}$ & 19.2 & $0^{*}$ & $\begin{array}{l}\text { metallic } \\
\text { white }\end{array}$ \\
\hline
\end{tabular}


The microstructure of the gold binary eutectic alloys is duplex, comprising a gold-rich phase, which in most cases is essentially pure gold, interspersed with the other constituent phase of the eutectic reaction. In gold-germanium and gold-silicon alloys (see Figures $5 a$ and $\mathbf{b}$ ), this latter phase is virtually pure germanium or silicon, respectively, while in gold-antimony it is the intermetallic phase, $\mathrm{AuSb}_{2}$, which is rich in antimony (see Figure $5 \mathrm{c}$ ). All these phases are silvery or metallic grey in colour and will whiten the alloy overall to an extent that is largely determined by their volume proportion. Thus, gold- $3 \mathrm{wt} \%$ silicon alloys contain 84 vol.\% of gold and 16 vol.\% silicon are golden colour, whereas gold- $25 \mathrm{wt} \%$ germanium alloys, with 68 vol. $\%$ of gold are lighter in hue and gold- $50 \mathrm{wt} \%$ antimony with 50 vol. $\% \mathrm{AuSb}_{2}$ are completely grey-white in colour (see Table 2 ). The gold $-20 \mathrm{wt} \%$ tin eutectic alloy shares most of these features but the constituent phases are $\zeta$, which approximates to $\mathrm{Au}_{5} \mathrm{Sn}$, and AuSn (Fig. 5d) and the alloy has no trace of a golden lustre whatsoever. The microstructure of an 18 carat gold solder $(75 \mathrm{Au}-25$ $\mathrm{Sb}$ wt\%) is shown in Figure 6. The duplex eutectic microstructure contains equal proportions of gold and metallic white phases so that the overall hue is much paler than the gold braze shown in Figure 3.

What is clear from these considerations is that the condition needed to achieve a yellow hue, namely a high volume percent of gold phase, runs counter to

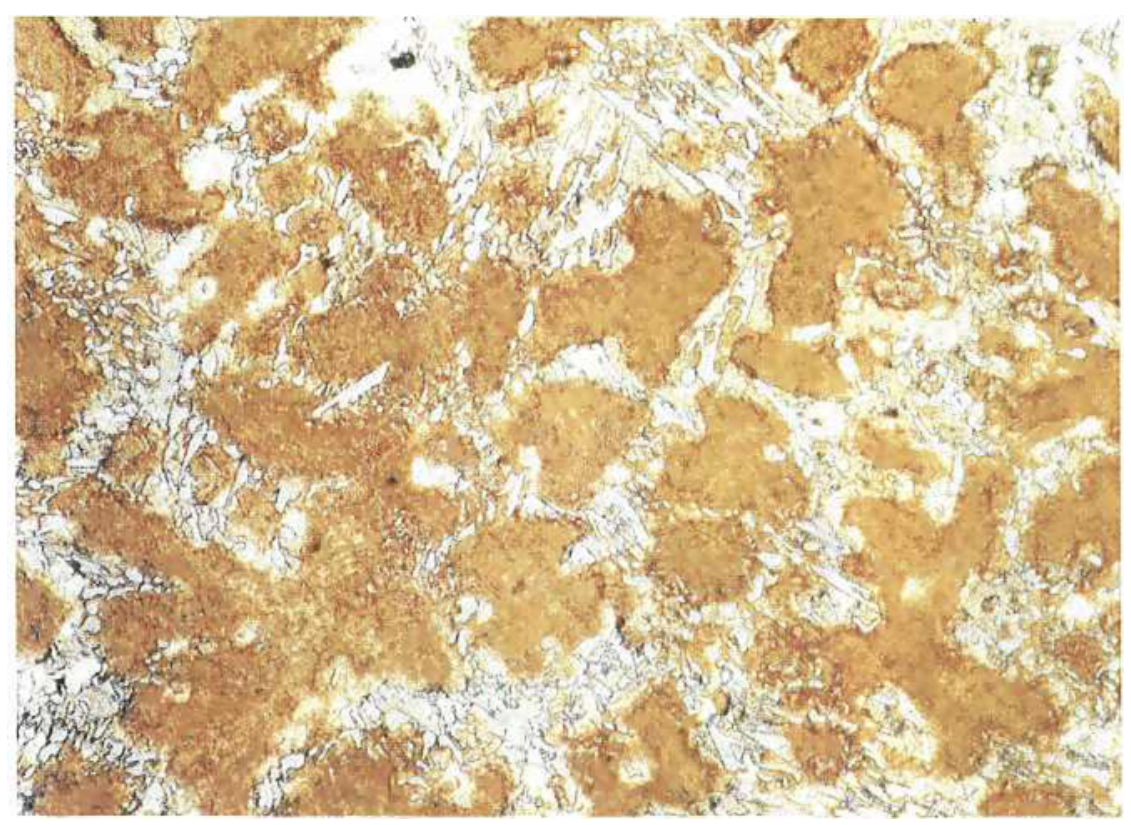

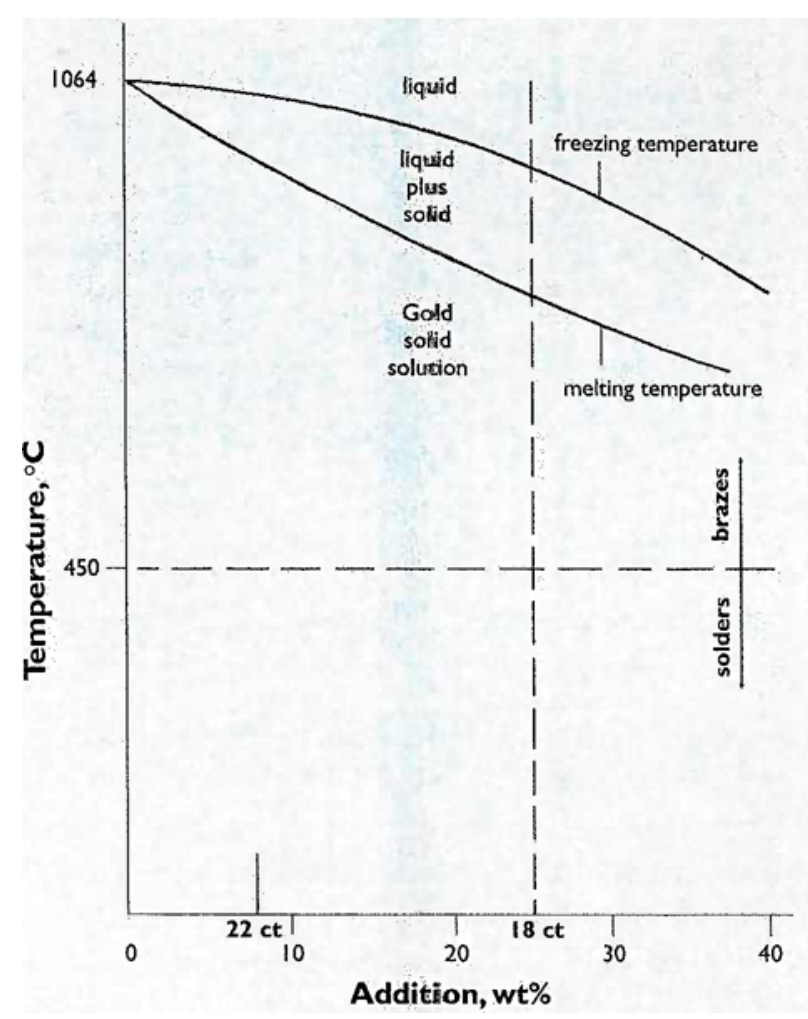

Figure 2

Phase diagram of a typical gold braze

the 75 weight percent gold specification of an 18 carat alloy because the elements that enter into eutectic equilibrium with gold have a much lower density (see Table 3). Thus, it follows that 18 carat gold alloys based on low melting point eutectics must have a base metal colour. It is not possible to compensate for the whitening effect of the base metal by adding the only other

Figure 3

Microstructure of an 18 carat gold braze (75Av-12Ni-5Sn-8Zn wt\%). The major phase is primary gold solid solution in a quaternary matrix (magnification x400). 
Table 3

Densities of the constituents of gold-rich binary eutectics

\begin{tabular}{|l|cc|}
\hline Element & $\begin{array}{c}\text { Density, } \\
\mathbf{k g m}^{-3}\end{array}$ & $\begin{array}{c}\text { Density of } \\
\text { element/ } \\
\text { density of } \\
\text { gold }\end{array}$ \\
\hline Gold & 19,000 & 1 \\
Silicon & 2,300 & 0.12 \\
Germanium & 5,400 & 0.28 \\
Tin & 7,300 & 0.238 \\
\hline
\end{tabular}

metal with a reddish colour, namely copper, to achieve better colour matching to gold. Copper reacts with all of the base metal constituents of the eutectic series to form intermetallic phases which are also dull grey or whitish in colour. Hence it is most unlikely that an 18 carat gold solder can be formulated so as to contain $75 \mathrm{wt} \%$ gold, have a melting point below $450^{\circ} \mathrm{C}$ and, simultaneously, a yellow gold hue. All other metals have a silvery or grey lustre and cannot restore a golden colour.

Another type of joining process must therefore be sought for application to 18 carat yellow gold jewellery fabrication at these temperatures, one of which is described below.

The fact that small percentages of base metal additions can considerably reduce the melting point of gold suggests that there might be scope for developing low melting point 22 carat solder pastes, based on the gold $-3 \mathrm{wt} \%$ silicon eutectic. This alloy finds application in the electronics industry for bonding silicon chips into metallised ceramic packages. The addition of up to $5 \mathrm{wt} \%$ of other elements is permissible within the hallmarking standard. Indeed such additions are desirable in order to minimise the value of precious metal present and also to improve the spreading characteristics of the alloy, which are otherwise poor. Initial trials have indicated that by careful selection of the base metal additions it is possible to realise colour-matched, low melting point 22 carat solders and the development of suitable fluxes and other ingredients to permit the formulation of pastes for use in air is currently in progress.

\section{A LOW TEMPERATURE JOINING PROCESS FOR I8 CARAT YELLOW GOLD: Diffusion Soldering}

Soldering and brazing offer several important advantages as joining methods. They are cheap in terms of the equipment and facilities required and are relatively fast to implement. They are also fairly tolerant to processing conditions and are capable of producing joints that are mechanically sound and aesthetically acceptable. It is therefore understandable that the jewellery industry finds these methods to be preferable to alternatives such as laser or electron beam welding, diffusion bonding and adhesive joining.

A recent development has led to a successful low temperature joining process for 18 carat gold that possesses the advantages of conventional soldering but which also offers other attractive capabilities, namely diffusion soldering.

Diffusion soldering is a hybrid of diffusion bonding and soldering. The principle of the process is to introduce a small, controlled volume of solder into

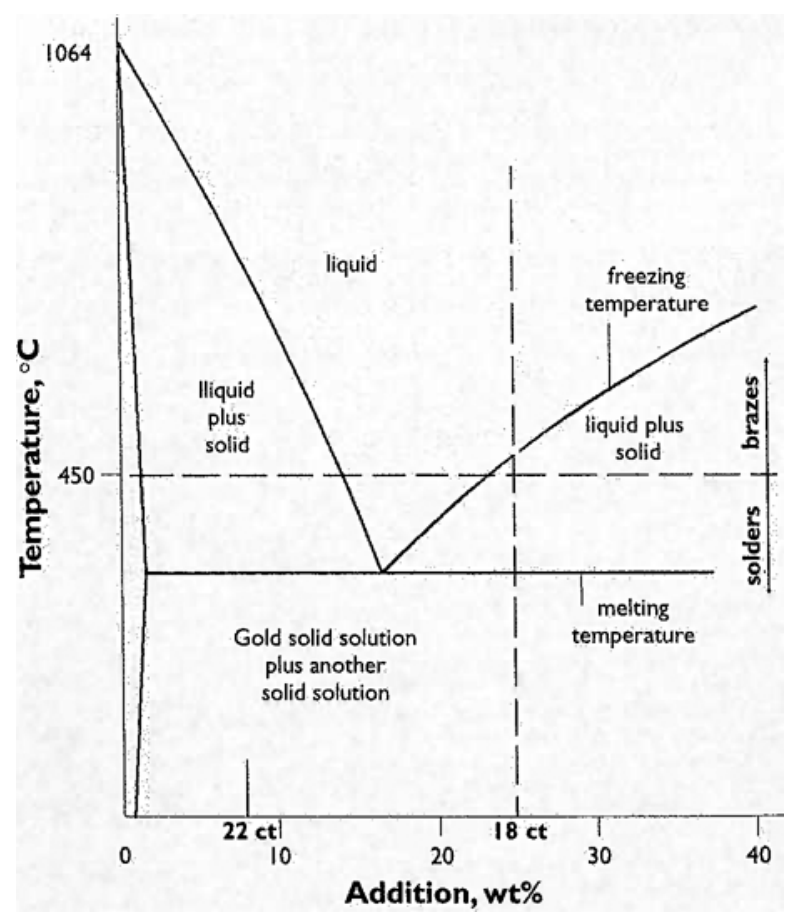

Figure 4

Phase diagram of a typical gold solder 


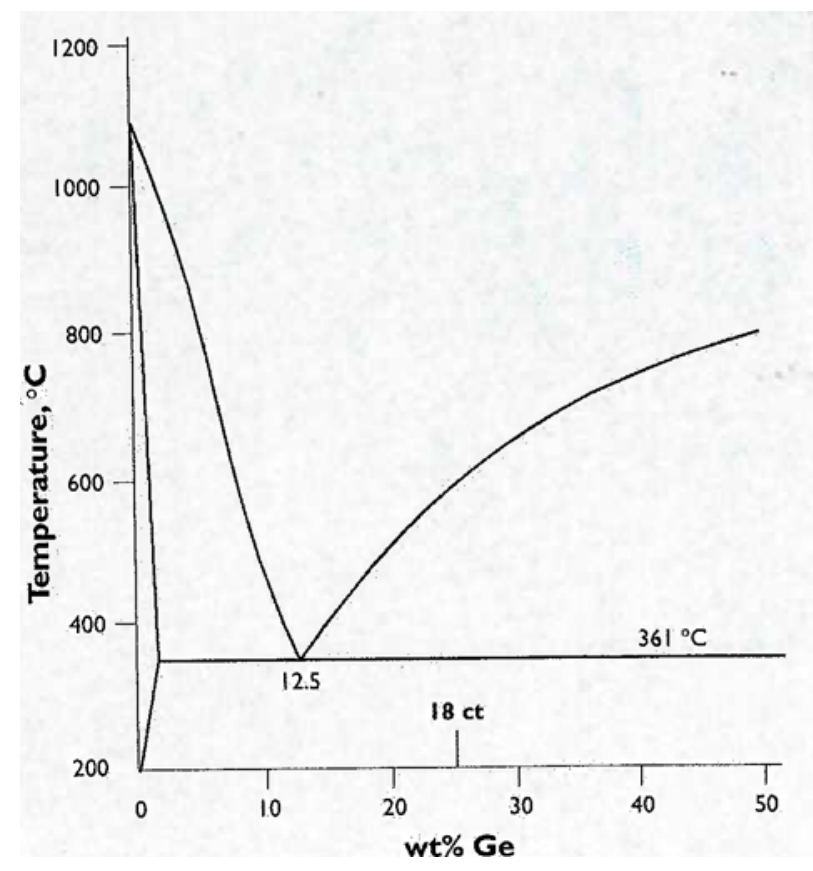

Figure 5a

Gold-rich end of the gold-germanium phase diagram

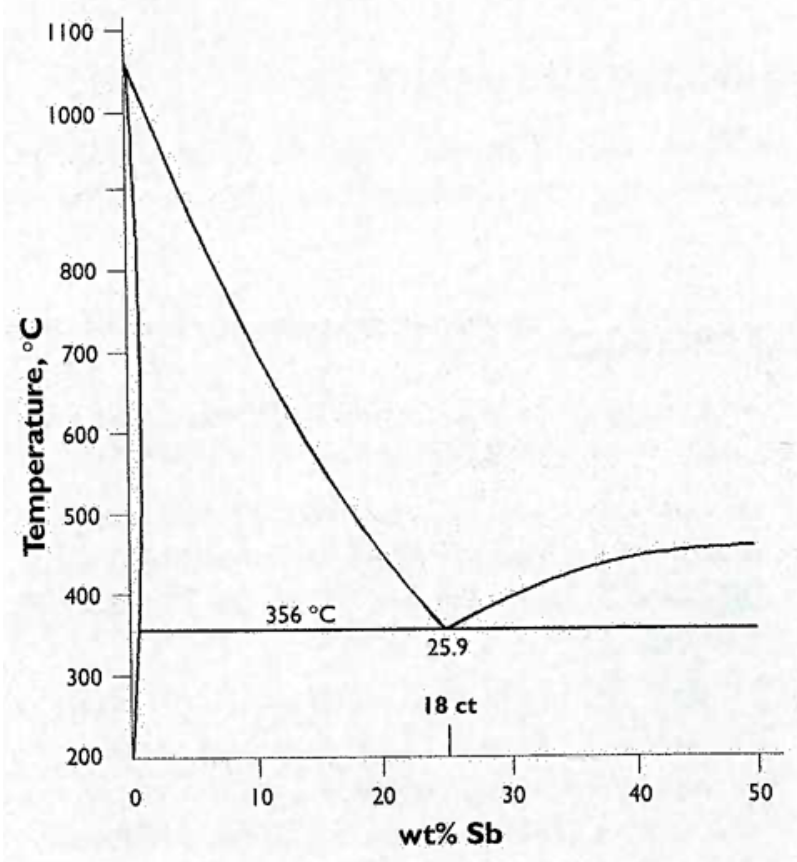

Figure 5c

Gold-rich end of the gold-antimony phase diagram

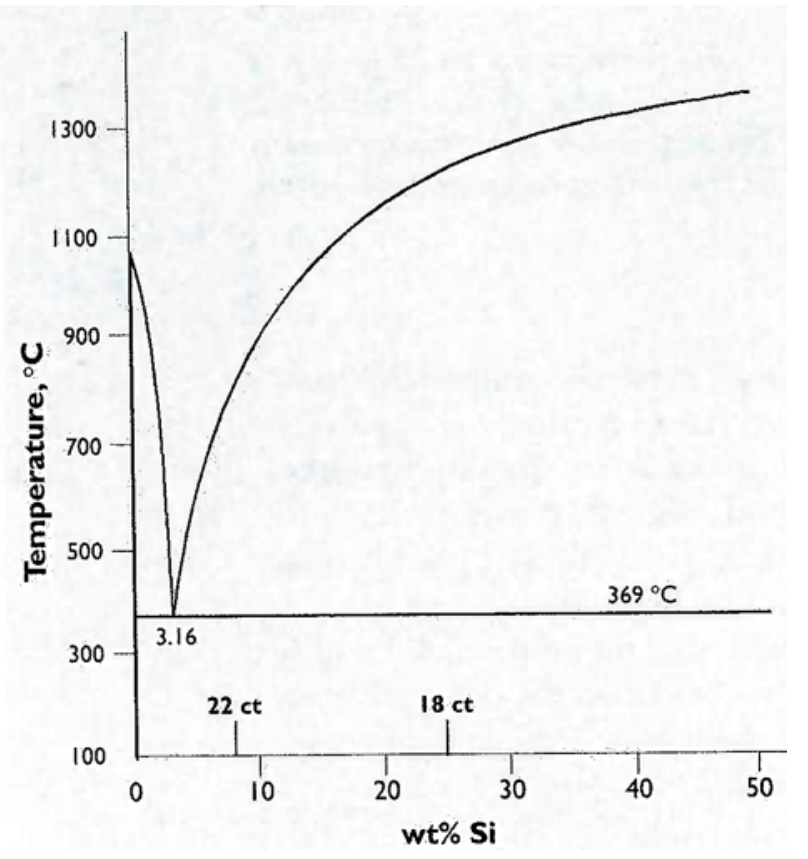

Figure $5 b$

Gold-rich end of the gold-silicon phase diagram

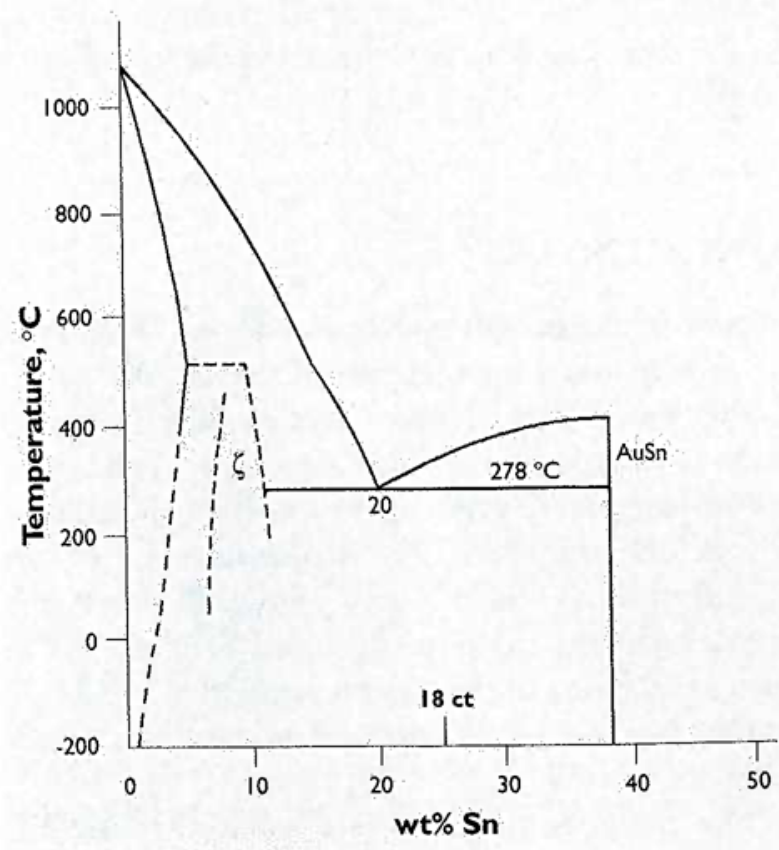

Figure $5 \mathrm{~d}$

Gold-rich end of the gold-tin phase diagram (in simplified form) 


\section{Figure 6}

Microstructure of an 18 carat gold solder (75Au-25Sb wt\%).

The alloy is close to the binary eutectic composition (magnification x400).

a joint between components that are pressed together and to solidify the solder at the joinning temperature through its conversion to high melting point phases by isothermal reaction with the parent metals. There- after the joint will not remelt unless heated to the temperature at which the high melting point phases melt [3],

It has been demonstrated that tin can be used to make diffusion soldered joints between components of 18 carat yellow gold [4]. Joints are made by heating the assembly to $450^{\circ} \mathrm{C}$, which allows the process to be classified as soldering. The resulting joints are colour matched and have mechanical properties that are adequate for jewellery applications. Diffusion soldering with tin has also been applied successfully to join 22 carat jewellery and the new jewellery alloy of 990 gold.

\section{CONCLUSIONS}

A review of the metallurgical constitution of 18 carat gold joining alloys has highlighted the fact that brazes meeting this caratage requirement are based on solid solutions of gold and are thereby colour matched to the complementary yellow gold jewellery alloy. In order to achieve sufficiently low temperatures for soldering operations $\left(<450^{\circ} \mathrm{C}\right)$ with high gold alloys, it is necessary for the fillers to be based on eutectics in which at least one of the participating phases is a base metal or intermetallic compound, which has a metallic grey or white hue.

The presence of base metal phases dilutes the golden colouration to an extent that at the $75 \mathrm{wt} \%$ gold content of 18 carat gold, the alloys have no golden hue. Thereby, it is possible to infer that a yellow, 18 carat gold solder is unlikely to exist, although a 22

carat alloy with all the requisite properties is possible. An alternative joining solution, which shares many of the beneficial features of soldering has been successfully developed for use with 18 carat yellow gold. This technology offers considerable potential for the jewellery industry.

\section{ACKNOWLEDGMENTS}

The World Gold Council is gratefully acknowledged for the funding of work on which this study is based.

\section{REFERENCES}

1. W.S. Rapson \& T. Groenewald, Gold Usage, Academic Press, pp. 80-85, 1978,

2. G. Humpston \& D.M. Jacobson, Principles of Soldering and Brazing, ASM International, Ohio, ISBN 0-87170-462-5, pp. 43-47, 54-58, 128-132, 1993

3. T. Isaac, M. Dollar \& T.B. Massalski, 'A Study of the Transient Liquid Phase Bonding Process Applied to $\mathrm{Ag} / \mathrm{Cu} / \mathrm{Ag}$ Sandwich Joint', Metallurgical Transactions A, 19A(3), pp. 675-686, 1988

4. G. Humpston, D.M. Jacobson \& S.P.S. Sangha, 'Diffusion Soldering: A New Low Temperature Process for Joining Carat Gold Jewellery', Gold Bull. 26(3), pp. 90-104, 1993 